\section{Adverse periocular reactions to five types of prostaglandin analogs}

K Inoue', M Shiokawa', R Higa', M Sugahara',

T Soga', M Wakakura ${ }^{1}$ and G Tomita ${ }^{2}$

\begin{abstract}
Purpose We investigated the appearance frequency of eyelid pigmentation and eyelash bristles after the use of five types of prostaglandin (PG) analogs.

Methods This study included 250 eyes from 250 patients diagnosed with primary openangle glaucoma or ocular hypertension who were treated with either latanoprost, travoprost, tafluprost, bimatoprost, or isopropyl unoprostone for $>3$ months in only one eye. Photographs of both eyes were obtained, and the images were assessed by three ophthalmologists who were masked to treatment type. The existence of eyelid pigmentation and eyelash bristles was judged, and images of the left and right eyes were compared. Subjective symptoms regarding the existence of eyelid pigmentation and eyelash bristles were investigated through a questionnaire. Results There was no significant difference between the five types of medications with regard to eyelid pigmentation $(P=0.537)$. Use of isopropyl unoprostone resulted in a significantly lower incidence of eyelash bristles $(P<0.0001)$. The questionnaire investigation showed that eyelid pigmentation and eyelash bristles were significantly more frequent with travoprost (42.0\% and $42.0 \%$, respectively) and bimatoprost $(58.0 \%$ and $60.0 \%$, respectively) than with other three medications $(P<0.0001)$.

Conclusion The appearance frequency of eyelid pigmentation was similar among the five types of PG analogs studied, and eyelash bristles appeared less frequently with isopropyl unoprostone use. Patients are conscious of eyelash bristles; therefore, these adverse effects should be sufficiently
\end{abstract}

explained to patients before PG administration. Eye (2012) 26, 1465-1472; doi:10.1038/eye.2012.195; published online 5 October 2012

Keywords: prostaglandin analogs; adverse reactions; eyelid pigmentation; eyelash bristles; patient's subjective evaluation; physician's subjective evaluation

\section{Introduction}

Prostaglandin (PG) analogs are the primary treatment for glaucoma because of their powerful intraocular pressure (IOP) decreasing effect, few systematic adverse reactions, and convenience of once a day administration (other than isopropyl unoprostone (unoprostone)). ${ }^{1}$

Five types of PG analogs (latanoprost, travoprost, tafluprost, bimatoprost, and unoprostone) are currently available in Japan.

Adverse reactions occurring around the eyes with PG analog use include conjunctival hyperemia, eyelash changes, eyelid pigmentation, iris pigmentation, hypertrichosis around the eyes, corneal epithelium disorder, appearance of iritis, cystoid macula edema, and deepening of the upper eyelid sulcus. ${ }^{2-16}$ Of these, changes in eyelashes, eyelid pigmentation, iris pigmentation, hypertrichosis around the eye, appearance of iritis, and deepening of the upper eyelid sulcus are thought to be characteristic adverse reactions to PG analogs. The frequency of eyelid pigmentation was reported to be between 0 and $25.9 \%,{ }^{2-9}$ and eyelash bristles are reported to occur in $0-77.0 \%$ of patients ${ }^{4-15}$ with PG analog use. However, no study has compared the frequency of occurrence of eyelid pigmentation
${ }^{1}$ Inouye Eye Hospital, Tokyo, Japan

${ }^{2}$ Second Department of Ophthalmology, Toho University School of Medicine, Tokyo, Japan

Correspondence: $\mathrm{K}$ Inoue, Inouye Eye Hospital, Medical Office, 4-3 Kanda-Surugadai, Chiyoda-ku, Tokyo 101-0062, Japan Tel: +81 332950911 ; Fax: +81 332950917 E-mail: inoue-k@ inouye-eye.or.jp

Received: 9 March 2012 Accepted in revised form: 19 August 2012 Published online: 5 October 2012 
and eyelash bristles with the use of five types of PG analogs.

In this study, we prospectively investigated the frequency of eyelid pigmentation and eyelash bristles with monocular administration of five types of PG analogs.

\section{Subjects and methods}

Subjects included 250 patients (105 men and 145 women) who were diagnosed with primary open-angle glaucoma, including normal tension glaucoma, or ocular hypertension. These patients were administered any of the five types of PG analogs (latanoprost, travoprost, tafluprost, bimatoprost, or unoprostone) in only one eye for $>3$ months, and were followed-up at the Inouye Eye Hospital from January through June 2011. Fifty corresponding patients were consecutively assigned to each group. Patient ages ranged between 28 and 86 years, and the mean age was $60.4 \pm 11.6$ years (mean \pm SD). Disease types included 238 cases of normal tension glaucoma, 10 cases of primary open-angle glaucoma, and 2 cases of ocular hypertension. The diagnostic criteria for normal tension glaucoma were IOP was under $21 \mathrm{~mm} \mathrm{Hg}$ measured several times, which include during diurnal variation, glaucomatous optic disc (diffuse or focal thinning of the neuroretinal rim), and highly reliable and repeatable detection of an abnormal glaucomatous visual field. We thought that decrease in IOP was needed, therefore eye drops were started. Unoprostone was administered twice a day (at morning and at night), while the other four types of PG analogs were administered once a day in the evening, and patients were directed to wash the face (eyelid) after administration. Patients were excluded if they had a cataract operation within the previous 3 months. Patients who had glaucoma surgery (trabeculectomy and/or trabeculotomy) were also excluded. All patients received an explanation of the procedures and possible risks of the study, and provided written informed consent. This study conformed to the Declaration of Helsinki and was approved by our ethical committee.

\section{Photography}

We photographed eyelids in opened and closed positions from the front using a Nikon D100 digital single lens reflex camera (Nikon, Tokyo, Japan). The images were recorded using an electronic filing system (VK-2 server; KOWA, Nagoya, Japan), and a dye-sublimation thermal transfer printer (CP900D; Mitsubishi, Tokyo, Japan) was used for printing. Photography was performed by four skilled operators.

\section{Questionnaire survey (patient's subjective evaluation)}

We conducted a written questionnaire addressing patients' subjective symptoms. The survey consisted of two questions: 'Did the lower eyelid become darker?' and 'Did eyelashes become thicker?' Possible answers were chosen from either 'lower eyelids became darker' and 'eyelashes became more bristled' or 'have not changed.'

\section{Appearance of adverse reactions (physician's subjective evaluation)}

Investigator-masked judgment was individually performed by three ophthalmologists who compared pictures of both eyes. The 255 cases (250 patients and 5 healthy subjects) were identifiable to the ophthalmologists only by serial numbers. All pictures of both the left and right eyes were compared and evaluated for the existence or non-existence of eyelid pigmentation and eyelash bristles. Eyelid pigmentation and eyelash bristle were defined by agreement of at least two of the three ophthalmologists. In addition, the photographs of five healthy people without any eye disease other than refractive errors served as controls.

\section{Comparison between cases where eyelid pigmentation and eyelash bristles appeared}

We investigated the disparity in objective evaluation, age, gender, administered eye, administration period, IOP, and mean deviation (MD) value using the Humphrey visual field program for the administered eye in cases where eyelid pigmentation and eyelash bristles did and did not appear.

\section{Statistics}

The appearance frequency rate was analyzed by $\chi^{2}$-test or Fisher's exact test. Mean differences were analyzed by $\chi^{2}$-test, Fisher's exact test, unpaired $t$-test, MannWhitney $U$-test, and Kruskal-Wallis test. A $P$-value of 0.05 was considered significant. The rate of concordance of the answers of the ophthalmologists was examined using the $\kappa$-factor in the physician's subjective evaluation. In the physician's subjective evaluation, appearances of eyelid pigmentation and eyelash bristles 
Table 1a Patient background

\begin{tabular}{|c|c|c|c|c|c|c|}
\hline & Latanoprost & Travoprost & Tafluprost & Bimatoprost & Unoprostone & P-value \\
\hline Age, mean \pm SD (range) & $\begin{array}{l}62.1 \pm 12.3 \\
(32-86)\end{array}$ & $\begin{array}{l}59.0 \pm 11.7 \\
(35-80)\end{array}$ & $\begin{array}{l}59.8 \pm 11.0 \\
(34-83)\end{array}$ & $\begin{array}{l}58.8 \pm 11.3 \\
(28-83)\end{array}$ & $\begin{array}{l}62.4 \pm 11.6 \\
(35-83)\end{array}$ & 0.3487 \\
\hline Gender, male: female & $23: 27$ & $20: 30$ & $26: 24$ & $19: 31$ & $17: 33$ & 0.3920 \\
\hline $\begin{array}{l}\text { Diagnosis, } \\
\text { NTG:POAG:OH }\end{array}$ & $47: 3: 0$ & $48: 1: 1$ & $45: 5: 0$ & $49: 0: 1$ & $49: 0: 1$ & 0.1972 \\
\hline Study eye, right: left & $25: 25$ & $26: 24$ & $\begin{array}{c}17: 33 \\
\quad * \\
\Gamma *\end{array}$ & $30: 20$ & $\begin{array}{c}21: 29 \\
1\end{array}$ & 0.0945 \\
\hline $\begin{array}{l}\text { IOP }(\mathrm{mm} \mathrm{Hg}) \\
\mathrm{MD}(\mathrm{dB})\end{array}$ & $\begin{array}{c}13.7 \pm 2.3 \\
-4.20 \pm 3.77\end{array}$ & $\begin{array}{c}13.7 \pm 2.6 \\
-4.44 \pm 4.86\end{array}$ & $\begin{array}{l}14.6 \pm 3.1 \\
-4.09 \pm 4.13 \\
\end{array}$ & $\begin{array}{c}13.3 \pm 2.5 \\
-4.56 \pm 4.56 \\
\end{array}$ & $\begin{array}{c}13.1 \pm 2.1 \\
-3.54 \pm 4.51 \\
\end{array}$ & $\begin{array}{l}0.0261 \\
0.8325\end{array}$ \\
\hline Duration (months) & $\begin{array}{l}59.4 \pm 31.8 \\
\|\| \bigsqcup\end{array}$ & $\begin{array}{c}17.0 \pm 10.9 \\
*\end{array}$ & $\begin{array}{c}10.9 \pm 6.2 \\
*\end{array}$ & 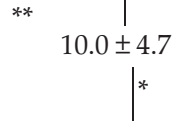 & ** $41.1 \pm 30.5$ & $<0.0001$ \\
\hline
\end{tabular}

${ }^{*} P<0.05 ;{ }^{*} P<0.0001$.

Table 1b Factors responsible for appearance of eyelid pigmentation and increased eyelash bristles

\begin{tabular}{|c|c|c|c|c|c|c|}
\hline & \multicolumn{3}{|c|}{ Eyelid pigmentation } & \multicolumn{3}{|c|}{ Eyelash bristle } \\
\hline & $\begin{array}{c}\text { Appeared } \\
(\mathrm{n}=10)\end{array}$ & $\begin{array}{l}\text { Did not appear } \\
\quad(\mathrm{n}=240)\end{array}$ & P-value & $\begin{array}{l}\text { Increased } \\
(\mathrm{n}=90)\end{array}$ & $\begin{array}{l}\text { Did not increase } \\
\qquad(\mathrm{n}=160)\end{array}$ & P-value \\
\hline Age, mean \pm SD & $59.1 \pm 13.1$ & $60.5 \pm 11.6$ & 0.8373 & $61.7 \pm 10.5$ & $59.7 \pm 12.1$ & 0.1716 \\
\hline Gender, male: female & $4: 6$ & $101: 139$ & $>0.9999$ & $39: 51$ & $66: 94$ & $>0.9999$ \\
\hline Administered eye, right: left & $6: 4$ & $113: 127$ & 0.5252 & $37: 53$ & $82: 78$ & 0.1469 \\
\hline $\mathrm{IOP}(\mathrm{mm} \mathrm{Hg})$ & $14.6 \pm 2.5$ & $13.6 \pm 2.6$ & 0.2271 & $14.0 \pm 2.9$ & $13.5 \pm 2.4$ & 0.209 \\
\hline $\mathrm{MD}(\mathrm{dB})$ & $0.20 \pm 1.61$ & $-0.46 \pm 1.76$ & 0.2696 & $-5.08 \pm 5.00$ & $-3.65 \pm 3.88$ & 0.0171 \\
\hline $\begin{array}{l}\text { Administered period } \\
\text { (months) }\end{array}$ & $34.1 \pm 34.1$ & $27.4 \pm 28.0$ & 0.2701 & $22.5 \pm 25.2$ & $30.6 \pm 29.5$ & 0.0296 \\
\hline
\end{tabular}

${ }^{*} P<0.05$.

were regarded as dependent variables, whereas eye drop type, age, gender, administered eye, administration period, IOP, and MD value were regarded as independent variables. Multiple logistic regression was used for analysis.

\section{Results}

\section{Patients}

There was no significant difference in mean age, gender, disease type, administered eye, or mean MD value among the five types of PG eye drops (Table 1a). The mean IOP of the administered eye was significantly higher in the tafluprost group than in the bimatoprost and unoprostone groups $(P=0.0261)$.

The mean administration period for the eye drops was significantly greater for latanoprost than for the other four medications $(P<0.05)$. The mean administration period was significantly greater for unoprostone than for travoprost, tafluprost, and bimatoprost $(P<0.0001)$.

\section{Appearance frequency of adverse reactions (physician's subjective evaluation)}

There was no significant differences in the frequency of eyelid pigmentation among the five types of PG analogs ( $P=0.537$; Figures 1 and 2a). Compared with the other four medication groups, the unoprostone group showed significantly less frequency of eyelash bristles $(P<0.0001$; Figures 1 and $2 b$ ). Each of the three ophthalmologists judged that eyelid pigmentation had appeared in 30, 20, and 8 cases each (all 3 matched for 3 cases); the lack of 

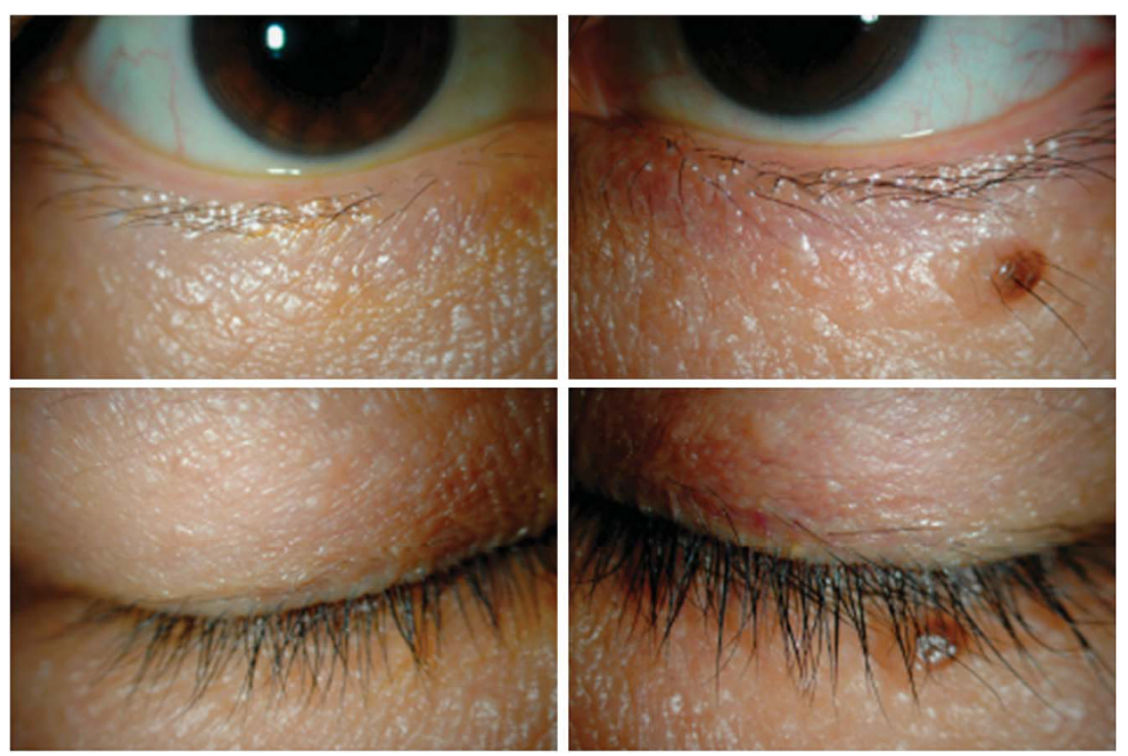

Figure 1 Cases of eyelid pigmentation and eyelash bristles. Bimatoprost group: left eye.

a
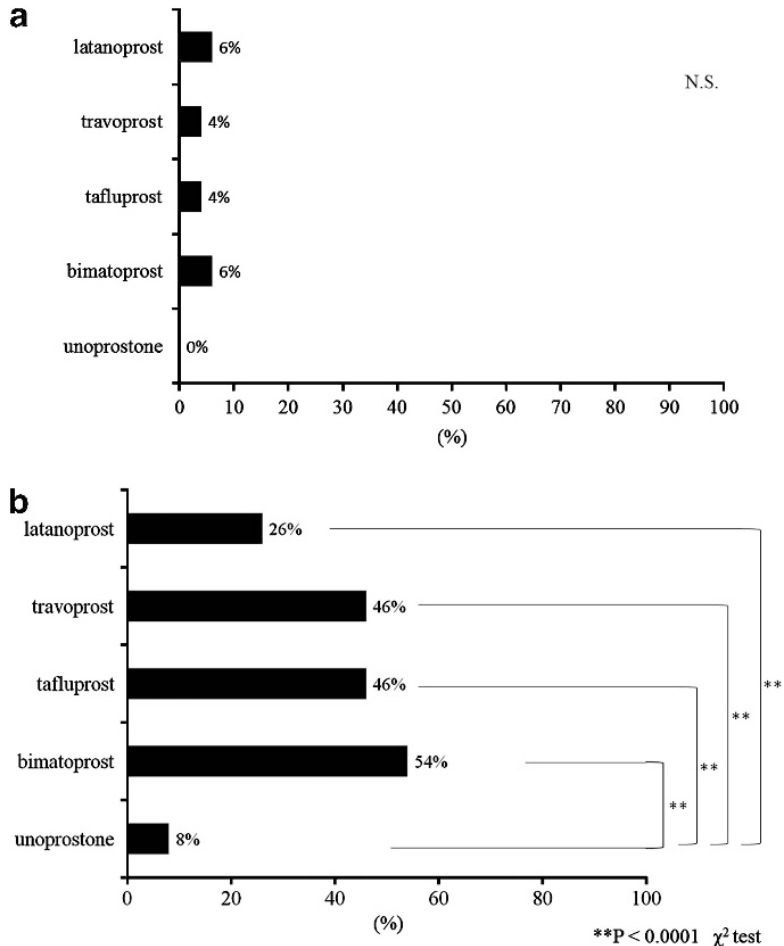

Figure 2 (a) Physician's subjective evaluation of eyelid pigmentation. There was no significant differences in the frequency of eyelid pigmentation among the five types of PG analogs $(P=0.537)$. (b) Physician's subjective evaluation of eyelash bristles $(* * P<0.0001)$. Compared with the other four medication groups, the unoprostone group showed significantly less frequency of eyelash bristles.

appearance of eyelid pigmentation was judged in 220, 230, and 242 cases each (all 3 matched for 205 cases). The judgment of the three ophthalmologists matched
( $\kappa$-factor 0.429). Each of the three ophthalmologists judged that eyelash bristles had appeared in 115, 107, and 49 cases each (all 3 matched for 36 cases). Therefore, the ophthalmologists did not identify eyelash bristles in 135, 143, and 201 cases (all 3 matched for 105 cases); the judgment of the three ophthalmologists matched ( $\kappa$ factor 0.429 ). Of the five healthy patients, none were identified as having eyelid pigmentation or eyelash bristles. There were no judgments of eyelid pigmentation, eyelash bristles, or adverse reactions in the non-administered eye.

\section{Self-written questionnaire (patient's subjective evaluation)}

Patients in the bimatoprost group answered 'lower eyelid became darker' significantly more frequently than did those in the latanoprost, tafluprost, and unoprostone groups $(P<0.0001$; Figure $3 a)$. Patients in the travoprost group answered 'eyelashes became bristled' significantly more frequently than did those in the unoprostone group $(P<0.0001$; Figure 3b). Patients in the bimatoprost group answered 'eyelashes became bristled' significantly more frequently than did those in the latanoprost, tafluprost, and unoprostone groups $(P<0.0001)$.

\section{Matching of patient's and physician's subjective evaluations}

In the physician's subjective evaluation, eyelid pigmentation appeared in three cases in the latanoprost group, and of these three cases, one patient answered 
a

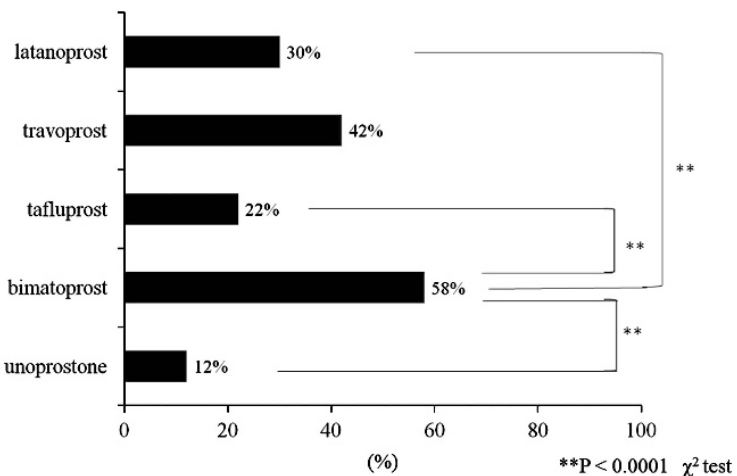

b

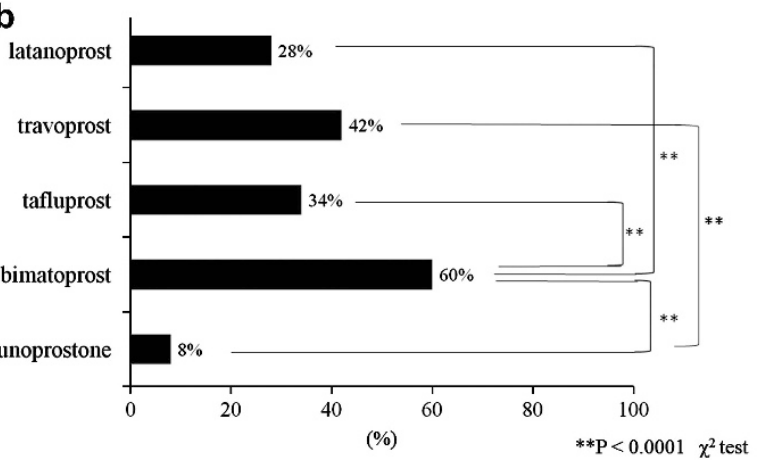

Figure 3 (a) Patient's subjective evaluation of eyelid pigmentation $\left.{ }^{* *} P<0.0001\right)$. Patients in the bimatoprost group answered 'lower eyelids became darker' significantly more frequently than did those in the latanoprost, tafluprost, and unoprostone groups. (b) Patient's subjective evaluation of eyelash bristles $\left({ }^{* *} P<0.0001\right)$. Patients in the travoprost group answered 'eyelashes became bristle' significantly more frequently than those in the unoprostone group.

'lower eyelid became darker' in the subjective evaluation (Figure 4a). Similarly, 2 out of 2 cases from the travoprost group, 0 out of 2 cases from the tafluprost group, and 2 of 3 cases from the bimatoprost group had matching patient's and physician's subjective evaluation for darkening eyelids. There were no qualifying cases in the unoprostone group. Thirteen cases of eyelash bristles appeared in the latanoprost group by physician's subjective evaluation, and of these 13 cases, 4 patients answered 'eyelashes became bristled' (Figure 4b). Furthermore, 10 of 23 cases from the travoprost group, 11 of 23 cases from the tafluprost group, 18 of 27 cases from the bimatoprost group, and 0 of 4 cases in the unoprostone group had matching patient's and physician's subjective evaluations with respect to eyelashes becoming bristled.

\section{Analysis of cases where eyelid pigmentation and eyelash bristles increased}

The age, gender, administered eye, administration period, IOP, and MD values were compared between the
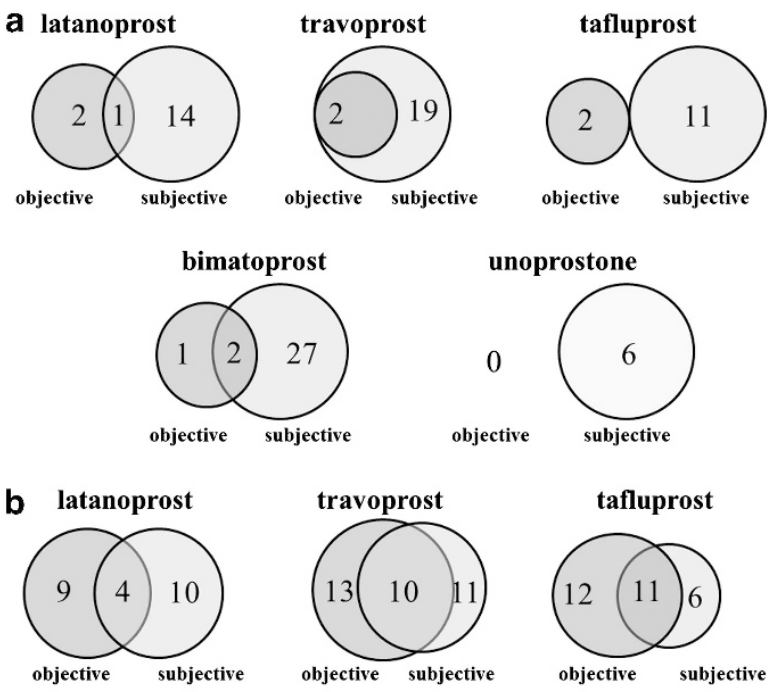

tafluprost
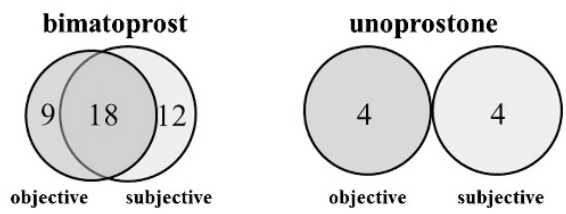

Figure 4 (a) Matching of patient's and physician's subjective evaluation: eyelid pigmentation. In the physician's subjective evaluation, eyelid pigmentation appeared in three cases in the latanoprost group, and of these three cases, one patient answered 'lower eyelid became darker' in the subjective evaluation. (b) Matching of patient's and physician's subjective evaluation: eyelash bristles. In all, 2 out of 2 cases from the travoprost group, 0 out of 2 cases from the tafluprost group, and 2 of 3 cases from the bimatoprost group had matching patient's and physician's subjective evaluation for darkening eyelids. There were no qualifying cases in the unoprostone group. Thirteen cases of eyelash bristles appeared in the latanoprost group by physician's subjective evaluation, and of these 13 cases, 4 patients answered 'eyelashes became bristled'.

cases in which eyelid pigmentation appeared (10 cases) and did not appear (240 cases); this comparison revealed no significant differences (Table $1 \mathrm{~b}$ ). The age, gender, administered eye, administration period, IOP, and MD value were compared between cases in which eyelash bristles appeared (90 cases) and did not appear (160 cases); the administration period was significantly shorter in cases in which bristles appeared than in cases in which they did not appear $(P<0.05)$. The MD value was significantly worse in cases in which bristles appeared than in cases in which they did not appear $(P<0.05)$

The types of eye drops, age, gender, administered eye, administration period, IOP, and MD value of cases where the appearance of eyelid pigmentation was identified were analyzed using multi-factor analysis; there was no related factors $(P=0.8008)$. On the other hand, the appearance of eyelash bristles was related to the 
administration period $(P=0.0330)$ and $\mathrm{MD}$ value

$(P=0.0283)$.

\section{Discussion}

The appearance frequencies of eyelid pigmentation with the use of PG analogs are reported to be $0,{ }^{2} 0.8,{ }^{3} 1.5,{ }^{4}$ $1.6,{ }^{5} 3.3,{ }^{6}$ and $5.9 \%{ }^{7}$ with latanoprost use; $2.9,{ }^{4}$ and $15.4 \%^{6}$ with travoprost use; and $1.6,{ }^{5} 2.9^{4}, 5.8,{ }^{3} 7.7{ }^{8}$ $17.8,{ }^{9}$ and $25.9 \%{ }^{6}$ with bimatoprost use. On the other hand, the appearance frequencies of changes in eyelashes were reported to be $0,{ }^{4} 0-46.2,{ }^{10} 0.7,{ }^{11} 3.2,{ }^{5}$ $4.4^{12} 25.8^{13} 28.7-50.5,{ }^{7} 36.7,{ }^{6}$ and $77.0 \%{ }^{14}$ with latanoprost use; $0.7,430.7,6$ and $57.1 \%{ }^{13}$ with travoprost use; and $2.9,{ }^{4} 4.5,{ }^{11} 12.6,{ }^{12} 25.6,{ }^{15} 42.8,{ }^{9} 46.2-53.8^{8},{ }^{8}$ and $48.1 \%{ }^{6}$ with bimatoprost use.

In these previous studies, ${ }^{2-15}$ there were variations in the frequency of the administration period, method used for judging adverse reactions (by slit lamp or images), and race. Owing to differences in the administration period, the appearance frequency of eyelid pigmentation was $1.5-2.9 \% 4$ in patients with $<3$ months of medication use and $0-25.9 \% \%^{2,3,5-8,15}$ in patients with $>3$ months of medication use. The appearance frequency of changes in eyelashes was $0-33.8 \% 4,10,12,15$ in patients with $<3$ months of use and $0.7-77 \%^{5-11,13,14}$ in patients with $>3$ months of use. In this study, the administration period was $>3$ months for all five types of PG analogs, and the appearance frequency ranged from 0 to $6.0 \%$ for eyelid pigmentation and 8.0 to $54.0 \%$ for eyelash changes. A longer administration period is thought to be associated with a higher appearance frequency. The method to determine adverse reactions was comparison of pictures of eyes obtained before and after administration or by examination at every check-up. The appearance frequency of eyelid pigmentation was $3.3-25.9 \%{ }^{6-9}$ by picture judgment and $0-5.8 \%{ }^{2-5}$ by slit lamp judgment at every check-up; this suggests that the appearance frequency determined by picture judgment is higher. The method of comparing pictures of the left eye with those of the right eye (0-6.0\%) provided results that were closer to the results obtained by slit lamp judgment. The frequency of changes in eyelashes by picture judgment was $0-53.8 \%^{6-10,12,13}$ and $0-25.6 \%$ by slit lamp judgment, $4,5,11,15$ indicating that the frequency was greater by picture judgment. The method of comparing pictures of the left eye with those of the right eye (8.0$54.0 \%$ ) in this study was closer to the picture judgments of previous studies.

There was no significant difference in age, gender, administered eye, administration period, and IOP between the cases in which eyelid pigmentation appeared and those in which it did not appear. On the other hand, the administration period was significantly shorter for cases in which eyelash bristles appeared (22.5 \pm 25.2 months) compared with those in which they did not appear ( $30.6 \pm 29.5$ months; $P=0.0296)$. There are possibilities that because eyelash bristles appeared, there were cases where administration was discontinued. The administration period may have been significantly shorter in patients in whom eyelash bristles appeared, because adverse reactions rarely appeared in patients who did not experience eyelash bristles; therefore, long-term use of eye drops was possible in patients who did not experience eyelash bristles.

In many cases wherein eyelash bristle was present, the MD value was not good when compared with the not appeared cases. This may be attributed to good adherence. On the other hand, eyelid pigmentation appeared because there might be possibilities that administration methods are more concerned than merits or demerits of adherence. Multi-factor analysis revealed that no specific factor was associated with eyelid pigmentation. In contrast, eyelash bristles were related to the administration period and the MD value of the administered eye for the reasons described above.

In this study, three ophthalmologists individually judged the appearance of eyelid pigmentation and eyelash bristles. The judgment ratio of the three ophthalmologists who judged the appearance of these characteristics matched in 3 of 10 cases for eyelid pigmentation and 36 of 90 cases for eyelash bristle. Dispersion is implicated in the method used in this study (comparison of pictures of the administered eye with those of the non-administered eye).

Limitations of this study include the possibility that judgments of eyelid pigmentation and eyelash bristles were not accurately performed in cases in which there were disparities between the original eyelids and eyelashes of the left and right eyes. The appearance of adverse reactions can be judged more accurately by comparing pictures of the eyes obtained before and after treatment, as noted in previous studies. ${ }^{6-10,12,13}$ In this study, we did not photograph the pictures of eyes before administration. Therefore, we were not able to compare pictures of before and after administration. Deepening of the upper eyelid sulcus and conjunctival hyperemia (other than eyelid pigmentation and eyelash bristle) may have been helpful for judgments. Moreover, there was a disparity between the administration periods of PG analogs; when comparing the appearance frequency of eyelid pigmentation and eyelash bristles for each type of eye drop, it is necessary to unify the administration periods. In addition, in cases where patients were administered the drug for a long period of 
time, adverse reactions may not have appeared objectively or subjectively and may have been in a stable state. We also did not establish a clear standard regarding the extent of disparities necessary in the left and right eyes to be considered an adverse reaction. As a result of this, the criteria of the individual ophthalmologists who judged the appearance of adverse reactions may have differed. There were no selection criteria for the PG analogs, and medication was selected by ophthalmologists; therefore, there may be a deviation in cases. In this study, we printed out the pictures for judgment, but if pictures where electronically projected and judged, there are possibilities that skin color control may be closer to the original.

To interpret a patient's tolerability to the appearance of eyelid pigmentation and eyelash bristles for each eye drop, a self-reported questionnaire was administered. When patient's and physician's subjective evaluations are compared, they matched in $44.0-88.0 \%$ of cases for eyelid pigmentation and in $52.0-84.0 \%$ cases for eyelash bristles. For eyelid pigmentation, the matching rate of the unoprostone group was significantly higher than those of the other four medications $(P<0.0001)$. The nonmatching rate of the bimatoprost group was significantly high $(P<0.0001)$ for eyelash bristles. Moreover, for eyelid pigmentation, results of subjective evaluation were higher than those of physician's subjective evaluation; this may indicate that patients are bothered by these bristles. One of the possible causes of this is that the appearance of adverse reactions was pointed out to patients before the administration of eye drops. The frequency of the appearance of eyelash bristles was not also equal by physician's and patient's subjective evaluation.

In the investigation of the appearance of eyelid pigmentation and eyelash bristles, eyelid pigmentation appeared in about 5\% of physician's subjective evaluations, and there were no significant frequency differences among the five types of PG analogs. The appearance frequency was higher by patient's subjective evaluation than by physician's subjective evaluation; from this we can tell that patients are concerned about appearance of adverse reactions. Eyelash bristles appeared in $8-54 \%$ of patients by physician's subjective evaluation. When compared with the other four medication groups, the unoprostone group showed a significantly low frequency of this side effect. By subjective evaluation, bimatoprost use showed the most frequent appearance of side effects.

In conclusion, when administering PG analogs, patients should be provided a sufficient explanation of eyelid pigmentation and eyelash bristles, and careful, long-term check-ups should be performed.

\section{Summary}

What was known before

- Prostaglandin analogs (PG) are the primary treatment for glaucoma because of their powerful intraocular pressure (IOP) decreasing effect, few systematic adverse reactions, and convenience of once a day administration (other than isopropyl unoprostone (unoprostone)).

\section{What this study adds}

- There was no significant difference in age, gender, administered eye, administration period, and IOP between the cases in which eyelid pigmentation appeared and those in which it did not appear. On the other hand, the administration period was significantly shorter for cases in which eyelash bristles appeared (22.5 \pm 25.2 months) compared with those in which they did not appear (30.6 \pm 29.5 months; $P=0.0296)$.

- There are possibilities that because eyelash bristles appeared, there were cases where administration was discontinued. The administration period may have been significantly shorter in patients in whom eyelash bristles appeared because adverse reactions rarely appeared in patients who did not experience eyelash bristles; therefore, long-term use of eye drops was possible in patients who did not experience eyelash bristles.

\section{Conflict of interest}

The authors declare no conflict of interest.

\section{References}

1 Cheng JW, Cai JP, Wei RL. Meta-analysis of medical intervention for normal tension glaucoma. Ophthalmology 2009; 116: 1243-1249.

2 Elgin U, Batman A, Berker N, Ilhan B. The comparison of eyelashes lengthening effect of latanoprost therapy in adults and children. Eur J Ophthalmol 2006; 16: 247-250.

3 Sharpe ED, Reynolds AC, Skuta GL, Jenkins JN, Stewart WC. The clinical impact and incidence of periocular pigmentation associated with either latanoprost or bimatoprost therapy. Cur Eye Res 2007; 32: 1037-1043.

4 Parrish RK, Palmberg P, Sheu W-P. A comparison of latanoprost, bimatoprost, and travoprost in patients with elevated intraocular pressure: a 12-week, randomized, masked-evaluator multicenter study. Am J Ophthalmol 2003; 135: 688-703.

5 Kampik A, Arias-Puente A, O'Brart DPS, Vuori M. The European latanoprost study group. Intraocular pressurelowering effects of latanoprost and brimonidine therapy in patients with open-angle glaucoma or ocular hypertension: a randomized observer-masked multicenter study. J Glaucoma 2002; 11: 90-96.

6 Birt CM, Buys YM, Ahmed IIK, Trope GE. The Toronto area glaucoma society. Prostaglandin efficacy and safety study undertaken by race (the pressure study). J Glaucoma 2010; 19: 460-467.

7 Inoue K, Wakakura M, Inoue J, Matsuo H, Hara T, Tomita G. Adverse reactions after use of latanoprost in Japanese glaucoma patients. Nippon Ganka Gakkai Zasshi (in Japanese) 2006; 110: 581-587. 
8 Inoue K, Shiokawa M, Sugahara M, Higa R, Wakakura M, Tomita G. Iris and periocular adverse reactions to bimatoprost in Japanese patients with glaucoma or ocular hypertension. Clin Ophthalmol 2012; 6: 111-116.

9 Manni G, Centofanti M, Parravano M, Oddone F, Bucci MG. A 6-month randomized clinical trial of bimatoprost $0.03 \%$ versus the association of timolol $0.5 \%$ and latanoprost $0.005 \%$ in glaucomatous patients. Grafe's Arch Clin Exp Ophthalmol 2004; 242: 767-770.

10 Chiba T, Kashiwagi K, Ishijima K, Furuichi M, Kogure S, Abe $\mathrm{K}$ et al. A prospective study of iridial pigmentation and eyelash changed due to ophthalmic treatment with latanoprost. Jpn J Ophthalmol 2004; 48: 141-147.

11 Noecker RS, Dirks MS, Choplin NT, Bernstein P, Batoosingh $\mathrm{AL}$, Whitecup SM et al. A six-month randomized clinical trial comparing the intraocular pressure-lowering efficacy of bimatoprost and latanoprost in patients with ocular hypertension or glaucoma. Am J Ophthalmol 2003; 135: 55-63.
12 Gandolfi S, Simmons ST, Sturm R, Chen K, VanDenburgh AM. Three-month comparison of bimatoprost and latanoprost in patients with glaucoma and ocular hypertension. Ad Ther 2001; 18: 110-121.

13 Netland PA, Landry T, Sullivan EK, Andrew R, Silver L, Weiner A et al. Travoprost compared with latanoprost and timolol in patients with open-angle glaucoma or ocular hypertension. Am J Ophthalmol 2001; 132: $472-484$.

14 Demitsu T, Manbe M, Harima N, Sugiyama T, Yoneda K, Yamada N. Hypertrichosis induced by latanoprost. J Am Acad Dermatol 2001; 44: 721-723.

15 Brandt JD, VanDenburgh AM, Chen K, Whitcup SM. Comparison of once-or twice-daily bimatoprost with twicedaily timolol in patients with elevated IOP. Ophthalmology 2001; 108: 1023-1032.

16 Miyake K, Ibaraki N. Prostaglandins and cystoid macular edema. Surv Ophthalmol 2002; 47(Suppl. 1): S203-S218. 